\title{
Arecoline inhibits epithelial cell viability by upregulating the apoptosis pathway: Implication for oral submucous fibrosis
}

\author{
MING LI ${ }^{1,2}$, FENG GAO $^{3,4}$, ZHONG-SU ZHOU ${ }^{2}$, HUI-MING ZHANG ${ }^{2}$, RUI ZHANG ${ }^{2}$, \\ YING-FANG WU ${ }^{1}$, MING-HAI BAI ${ }^{2}$, JI-JIA LI ${ }^{1}$, SHI-RONG LIN ${ }^{5}$ and JIE-YING PENG ${ }^{1}$ \\ ${ }^{1}$ Dental Medical Center, Xiangya Hospital of Central South University; ${ }^{2}$ Changsha Stomatological Hospital; \\ ${ }^{3}$ Powder Metallurgy Research Institute of Central South University; ${ }^{4}$ The Third Xiangya Hospital of Central South University, \\ Changsha, Hunan, P.R. China; ${ }^{5}$ Taiwan Taipei Dental Sciences, Taipei, Taiwan, R.O.C.
}

Received December 29, 2013; Accepted February 20, 2014

DOI: $10.3892 /$ or.2014.3091

\begin{abstract}
Oral submucous fibrosis (OSF) is a chronic inflammatory disease characterized by the accumulation of excess collagen, and areca nut chewing has been proposed as a significant etiological factor for disease manifestation. However, the underlying molecular mechanisms regarding areca nut chewing-induced OSF are only partially understood. Herein, we reported that arecoline markedly induced morphologic change in HaCaT epithelial cells, but had no obvious effect on Hel fibroblast cells. MTS assay revealed that arecoline significantly suppressed $\mathrm{HaCaT}$ cell viability. Moreover, flow cytometric analysis indicated that arecoline substantially promoted $\mathrm{HaCaT}$ cell, but not Hel cell apoptosis in a dosedependent manner. Furthermore, arecoline-induced $\mathrm{HaCaT}$ cell apoptosis was found to be associated with increased expression and activation of cleaved-Bid, cleaved-PARA and cleaved-caspase-3. Collectively, our results suggest that $\mathrm{HaCaT}$ epithelial cells are more sensitive than Hel fibroblast cells to arecoline-induced cytotoxicity, which may be involved in the pathogenesis of OSF.
\end{abstract}

\section{Introduction}

OSF is a chronic insidious disease which is predominantly found in individuals of Asian descent $(1,2)$. OSF is predisposing to cancer, and the rate of carcinoma incidence in OSF cases reaches to $7.6 \%$ (3). The hallmark of this disease is submucosal progressive fibrosis that affects the upper digestive tract

Correspondence to: Professor Jie-Ying Peng, Dental Medical Center, Xiangya Hospital, Central South University, Changsha, Hunan 410008, P.R. China

E-mail: jieyingpengxy@gmail.com

Abbreviations: OSF, oral submucous fibrosis; BQ, betel quid; OSCC, oral squamous cell carcinoma; ANE, areca nut extract; PARP, poly(ADP-ribose) polymerase

Key words: oral submucous fibrosis, arecoline, apoptosis, Bid, caspase-3 involving the oral cavity, oropharynx and the upper third of the esophagus. Histologically, most OSF cases are characterized by epithelial atrophy and accumulation of collagen fibers in the lamina propria while a minority is characterized by epithelial atypical hyperplasia and progressive loss of vascularity. The majority of patients are intolerant to spicy foods, and experience a burning sensation in the mouth, xerostomia, and limitation of mouth opening, swallowing and tongue movement (4-8). Epidemiologic studies have indicated that betel quid (BQ) chewing is one of the major risk factors of OSF and oral squamous cell carcinoma (OSCC) (9-12). Arecoline, the most abundant areca alkaloid, has been suggested as a possible carcinogen which was found to be cytotoxic and genotoxic in several types of cells (13-17). However, the mechanisms which are responsible for arecoline-induced OSF and carcinogenesis are not fully known.

Apoptosis is one of the major forms of programmed cell death which is dependent on caspase activity (18). This death program can be elicited by different extracellular or intracellular stimuli that activate common downstream cell-death machinery. The extrinsic pathway, also known as the direct, or type I pathway, is triggered by the ligand-induced activation of cell membrane-anchored death receptors, and finally induces caspase- 8 cleavage and activation (19). The intrinsic pathway is activated by cellular damage in which the mitochondrion plays a central role and eventually activates caspase-9 (20-22). Both cleaved-caspase- 8 and caspase- 9 further regulate other caspase members, including caspase-3 and caspase-7, to initiate a caspase cascade leading to apoptosis (23). Bid was first cloned in 1996 as a novel death agonist that heterodimerizes with either agonists (Bax) or antagonists (Bcl-2) (24). Bid is localized in the cytosolic fraction of cells as an inactive precursor. Caspase- 8 cleaves Bid at aspartic acid residue 60 (Asp60), leading to the release of a truncated form containing the carboxy-terminal part of the protein (25). Cleaved Bid (tBid) translocates to mitochondria and initiates mitochondrial outer membrane permeabilization (MOMP), and eventually induces cytochrome $c$ release and mitochondrial damage $(26,27)$. Thus, Bid relays an apoptotic signal from the cell surface to the mitochondria.

In the present study, we investigated the effects of arecoline on the HaCaT epithelial and Hel fibroblast cell lines. First, 
human keratinocyte cells of the HaCaT cell line and human embryo lung fibroblasts of the Hel cell line were exposed to high doses of arecoline for a short time to observe the survival rate and apoptosis. Secondly, the molecular mechanism of arecoline-induced HaCaT cell apoptosis was studied.

\section{Materials and methods}

Reagents and antibodies. Arecoline was purchased from Sigma (St. Louis, MO, USA). Antibodies to detect cleavedPARP (9541), caspase-3 (9665) and Bid (2002) were purchased from Cell Signaling Technology, Inc. (Beverly, MA, USA). The antibody against $\beta$-actin was purchased from Santa Cruz Biotechnology (Santa Cruz, CA, USA).

Cell culture. Keratinocytes of the naturally immortalized normal cell line, HaCaT, and the human embryonic lung fibroblast cell line (human normal fibroblast cell line), Hel, were kindly provided by the College of Life Science, Hunan Normal University, China. HaCaT and Hel cells were grown in Dulbecco's modified Eagle's medium supplemented with $10 \%$ FBS (Invitrogen, Carlsbad, CA, USA), $100 \mathrm{U} / \mathrm{ml}$ penicillin, and $100 \mathrm{mg} / \mathrm{ml}$ streptomycin and cultured at $37^{\circ} \mathrm{C}$ in a humidified incubator with $5 \% \mathrm{CO}_{2}$.

Cell proliferation assay. Cells were seeded (5x10 $3 /$ well) in 96-well plates and incubated for $24 \mathrm{~h}$ and then exposed to different doses of arecoline. After incubation for 12, 24, 48 or 72 h, $20 \mu \mathrm{l}$ of CellTiter 96 Aqueous One Solution (Promega, Madison, WI, USA) was added, and then cells were incubated for $1 \mathrm{~h}$ at $37^{\circ} \mathrm{C}$ in a $5 \% \mathrm{CO}_{2}$ incubator. Absorbance was measured at $492 \mathrm{~nm}$.

Apoptosis and flow cytometric analysis. Cells $\left(2 \times 10^{5}\right)$ were seeded into 6-well plates and treated without or with different concentrations of arecoline for $24 \mathrm{~h}$. Cells were trypsinized and washed twice with cold PBS and then resuspended in $1 \mathrm{X}$ Binding Buffer containing Annexin V-fluorescein isothiocyanate (FITC) and propidium iodide according to the supplier's instructions (BD Biosciences, San Jose, CA, USA). The cells were incubated for $15 \mathrm{~min}$ at room temperature $\left(20-25^{\circ} \mathrm{C}\right)$ in the dark and assessed by flow cytometry using a BD FACS Calibur cytometer as soon as possible (within $1 \mathrm{~h}$ ). Each sample was run twice.

Western blot analysis. Cells were harvested by trypsinization and pelleted by centrifugation. Cell pellets were lysed in NP-40 lysis buffer supplemented with protease inhibitors. Protein concentrations were determined using the Bradford assay (Bio-Rad Laboratories, Philadelphia, PA, USA). Proteins were separated by SDS-PAGE and electrically transferred to polyvinylidene difluoride membranes (Millipore, Billerica, MA, USA). After blocking in 5\% non-fat dry milk in TBS, the membranes were hybridized to specific primary antibodies overnight at $4^{\circ} \mathrm{C}$, washed three times with TBS Tween-20, and then incubated with secondary antibodies conjugated with horseradish peroxidase for $1 \mathrm{~h}$ at room temperature. Next, the membranes were washed three times in TBS Tween-20 at room temperature. The protein bands were visualized using ECL chemiluminescence reagents
(Pierce Chemical Co., Rockford, IL, USA) according to the manufacturer's protocol.

Statistical analysis. All the statistical analyses were performed using SPSS software (version 13.0). The experiments were performed in triplicate. The quantitative data are expressed as mean values \pm standard deviation. The significant differences between two groups were assessed by a two-tailed Student's t-test. $\mathrm{P}<0.05$ was considered to represent a statistically significant difference.

\section{Results}

Effect of arecoline on HaCaT and Hel cell morphology. In the present study, we first examined the effect of arecoline on $\mathrm{HaCaT}$ and Hel cell morphology. Exposure of HaCaT cells to different concentrations of arecoline for $48 \mathrm{~h}$ markedly induced changes in cell morphology. Our results showed that $0.1 \mathrm{mM}$ arecoline had no obvious cytotoxic effect on $\mathrm{HaCaT}$ cells (Fig. 1A and B). However, after we exposed HaCaT cells to higher concentrations of arecoline from 0.2 to $0.5 \mathrm{mM}$ for $48 \mathrm{~h}$, we found that a significant proportion of cells became detachment and round in shape. The number of rounded cells increased proportionally to the arecoline concentration, suggesting a dose-dependent effect of arecoline on the $\mathrm{HaCaT}$ cells. Additionally, high concentrations of arecoline directly induced $\mathrm{HaCaT}$ cell death. There was massive cell death and a lack of margins between the cells when the concentration of arecoline was increased to $0.3,0.4$ and $0.5 \mathrm{mM}$ (Fig. 1C-F). In contrast, the Hel cells were less affected by arecoline exposure. Even when the concentration of arecoline was increased to 0.4 and $0.5 \mathrm{mM}$, the Hel cells were still alive and the cell margins were bright and compact; the morphology began to change slightly (Fig. 2). Taken together, these data indicate that arecoline had a dose-dependent effect on HaCaT cell morphology but not on Hel cell morphology.

Arecoline inhibits the proliferation of HaCaT cells. Based on our results, we next determined the effect of arecoline on $\mathrm{HaCaT}$ and Hel cell growth. As expected, incubation with arecoline significantly reduced the viability of $\mathrm{HaCaT}$ cells in a dose- and time-dependent manner. Exposure to $0.2 \mathrm{mM}$ arecoline for $24 \mathrm{~h}$ began to inhibit $\mathrm{HaCaT}$ cell proliferation. Moreover, exposure to relatively high concentrations $(0.4$ and $0.5 \mathrm{mM}$ ) of arecoline for $72 \mathrm{~h}$ inhibited the viability of almost all of the HaCaT cells (Fig. 3A). However, arecoline had no such extensive effect on Hel cells. Only high concentrations $(0.4$ and $0.5 \mathrm{mM})$ of arecoline reduced the viability of $\mathrm{Hel}$ cells (Fig. 3B). Collectively, these results suggest that arecoline inhibits the proliferation of $\mathrm{HaCaT}$ epithelial cells, but not $\mathrm{Hel}$ fibroblasts.

Arecoline induces HaCaT cell apoptosis. To further investigate whether arecoline-induced $\mathrm{HaCaT}$ cell morphological change is due to apoptosis, we monitored the impact of different concentrations of arecoline on cell apoptosis by flow cytometric analysis. Our results demonstrated that exposure to 0.1 $\mathrm{mM}$ arecoline did not result in $\mathrm{HaCaT}$ cell apoptosis, consistent with our previous data that a low concentration of arecoline had no obvious effect on HaCaT cell morphology. However, in 

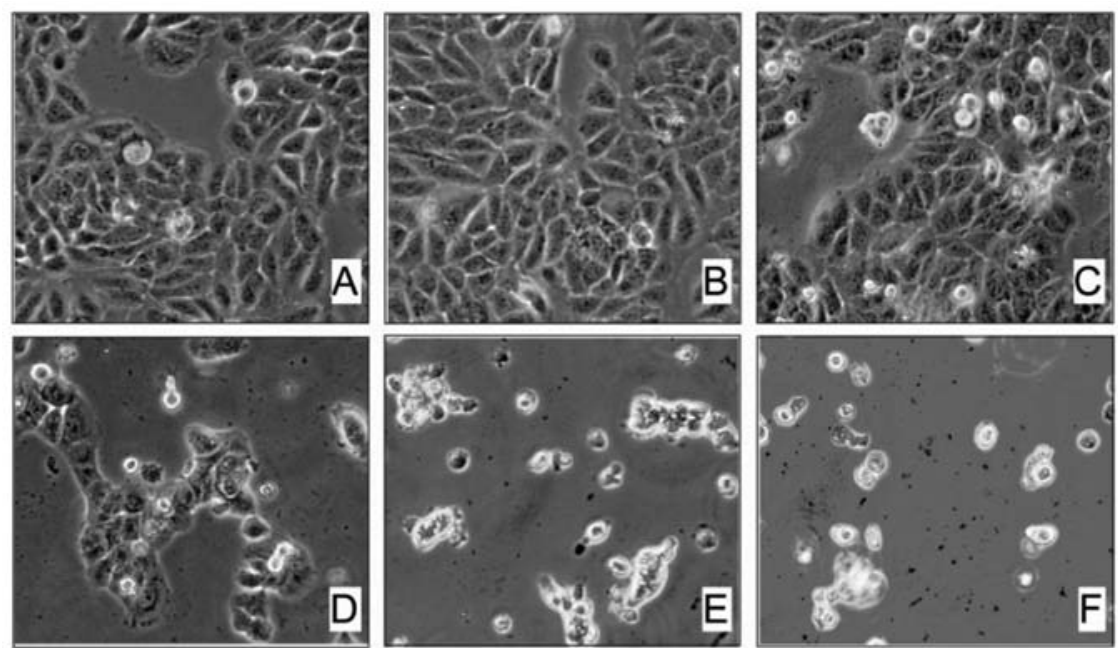

Figure 1. Effects of arecoline on the cell morphology of HaCaT cells. Arecoline affects the morphology of HaCaT epithelial cells in a dose-dependent manner. $\mathrm{HaCaT}$ epithelial cells were seeded in 6-well plates, and after reaching 70\% confluency, the cells were treated with various concentrations of arecoline for $48 \mathrm{~h}$. The representative images are shown from three independent experiments (magnification, x100). Concentrations of arecoline: (A) untreated, (B) $0.1 \mathrm{mM}$, (C) $0.2 \mathrm{mM}$, (D) $0.3 \mathrm{mM}$, (E) $0.4 \mathrm{mM}$, and (F) $0.5 \mathrm{mM}$.
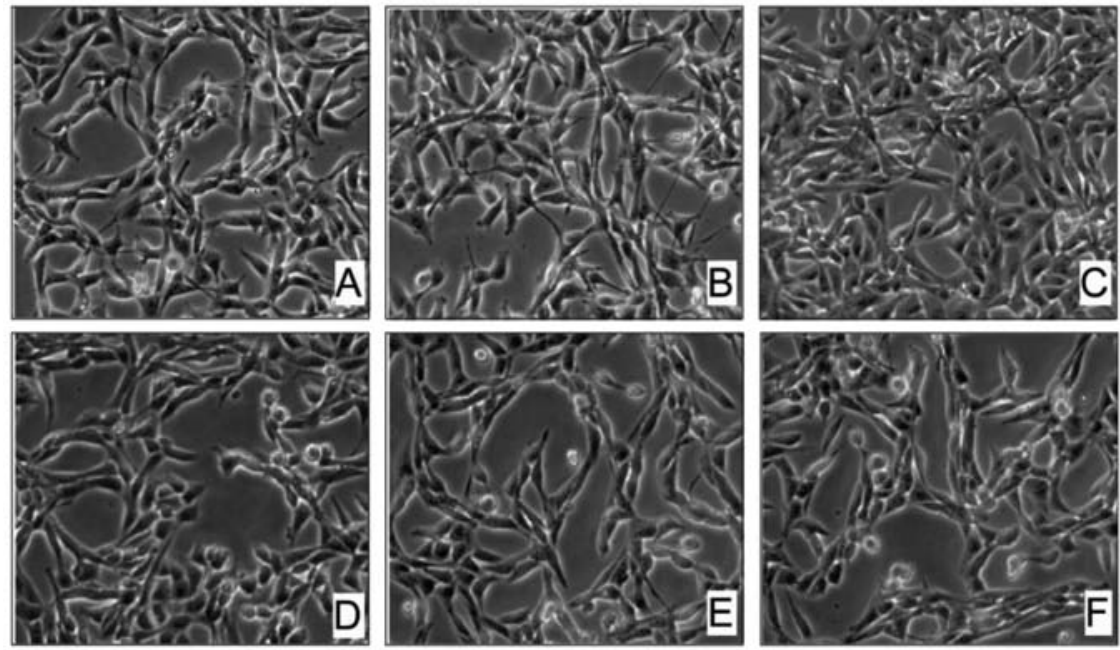

Figure 2. Effects of arecoline on the cell morphology of Hel cells. Arecoline did not observably induce a change in the morphology of Hel fibroblast cells Hel fibroblast cells were seeded in 6-well plates, and after reaching $70 \%$ confluency, the cells were treated with various concentrations of arecoline for $48 \mathrm{~h}$ The representative images are shown from three independent experiments (magnification, x100). Concentrations of arecoline: (A) untreated, (B) $0.1 \mathrm{mM},(\mathrm{C})$ $0.2 \mathrm{mM}$, (D) $0.3 \mathrm{mM}$, (E) $0.4 \mathrm{mM}$, and (F) $0.5 \mathrm{mM}$.

A

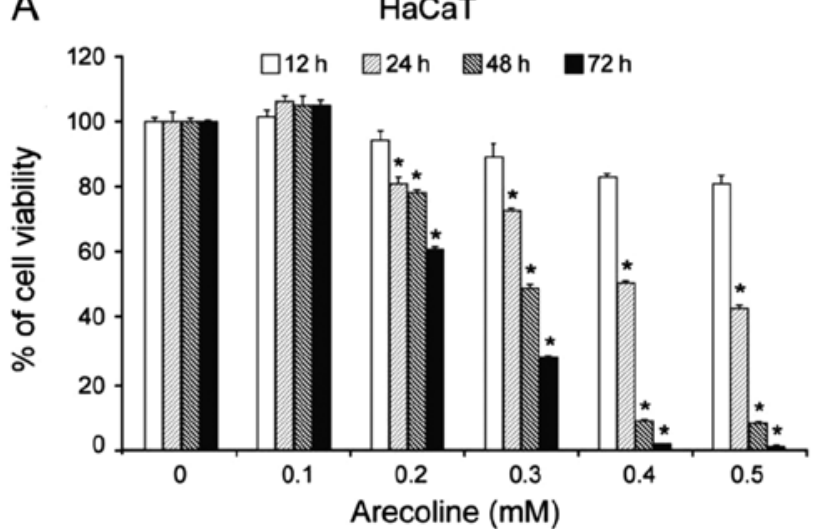

B

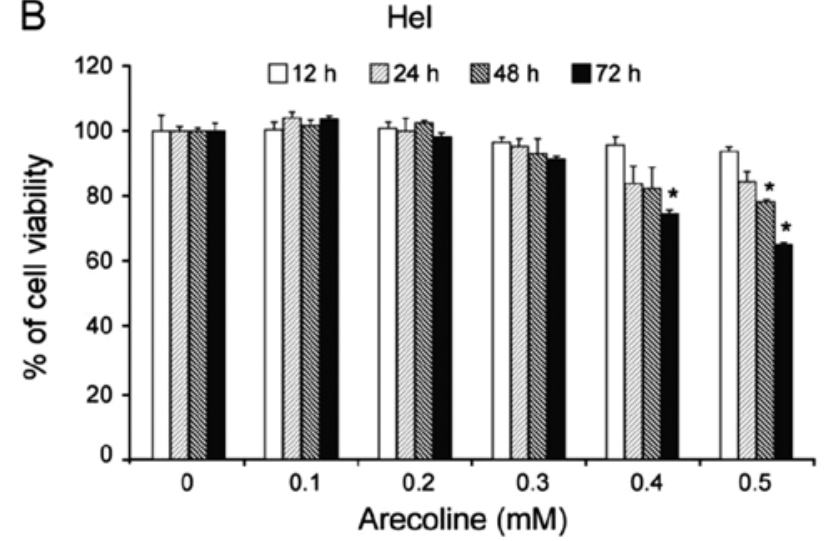

Figure 3. Effects of arecoline on the cell viability of $\mathrm{HaCaT}$ and Hel cells. (A) HaCaT and (B) Hel cells were exposed or not exposed to the indicated concentrations of arecoline for $12,24,48$ or $72 \mathrm{~h}$, and cell viability was determined by the MTS assay. Data are shown as means \pm SD of three independent experiments. *A significant $(\mathrm{P}<0.01)$ decrease in viability compared with the untreated control. 

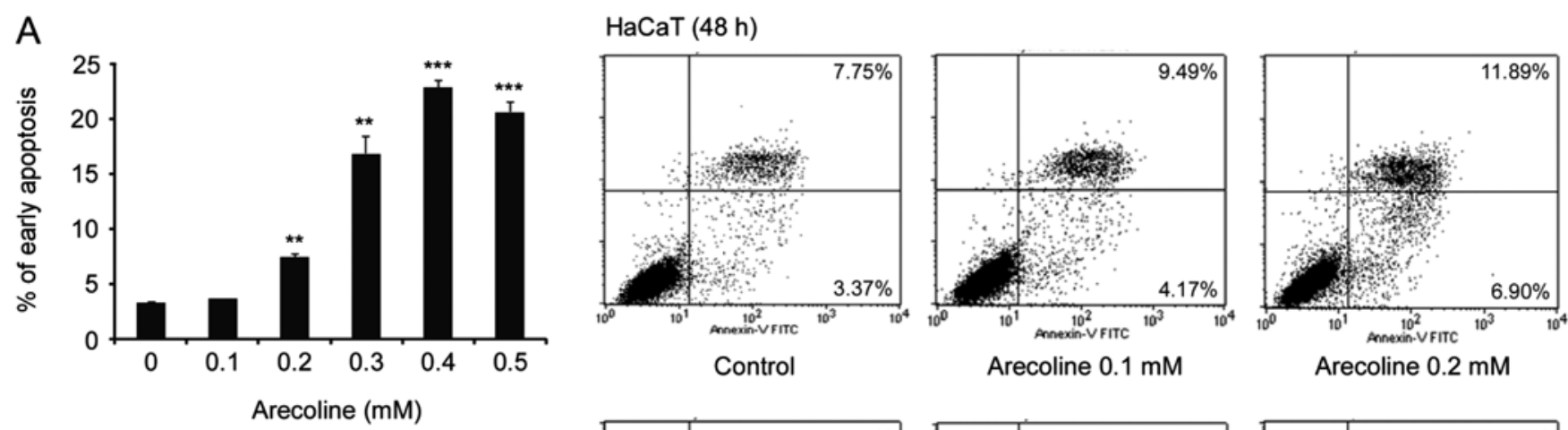

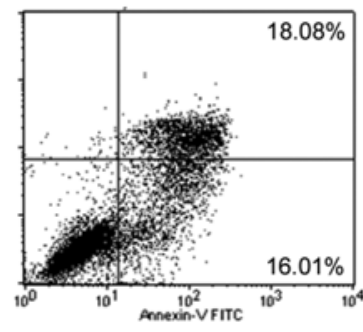

Arecoline $0.3 \mathrm{mM}$

Hel $(48 \mathrm{~h})$
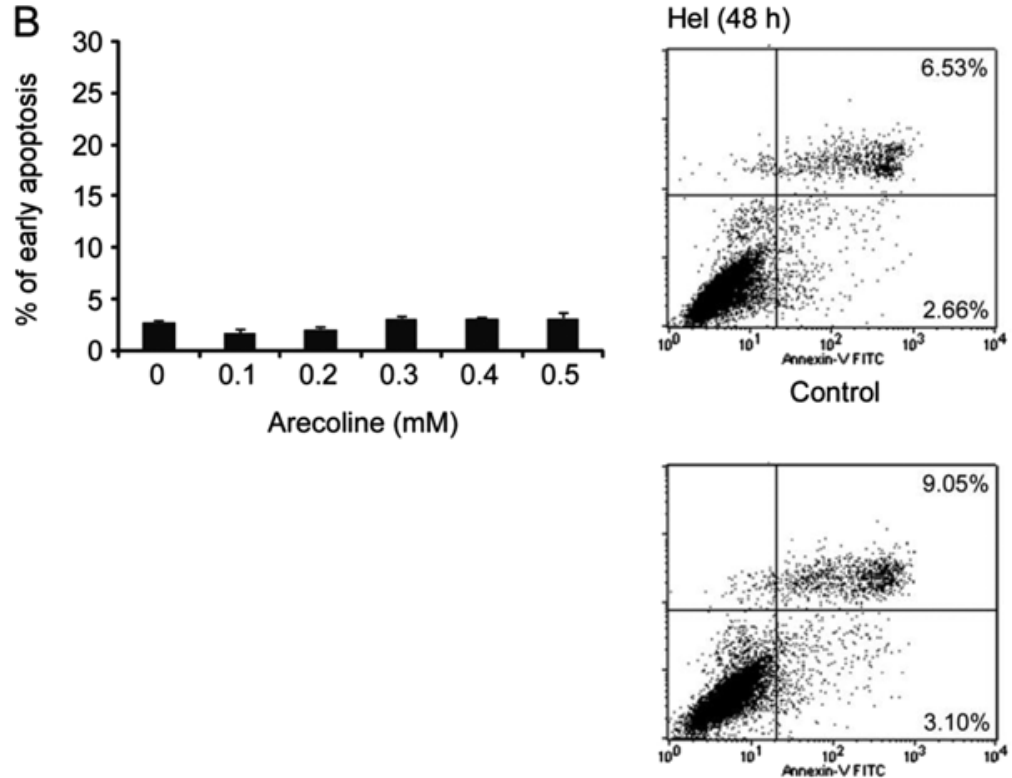

Arecoline $0.3 \mathrm{mM}$

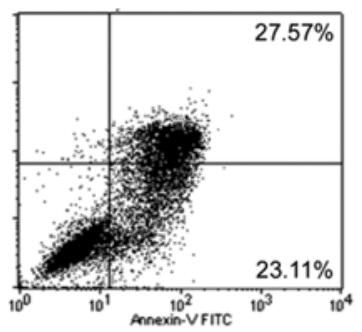

Arecoline $0.4 \mathrm{mM}$

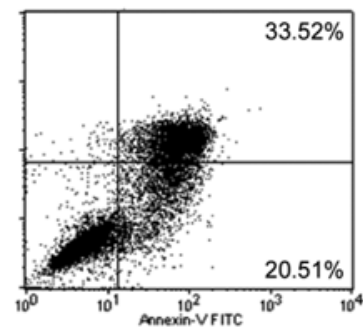

Arecoline $0.5 \mathrm{mM}$

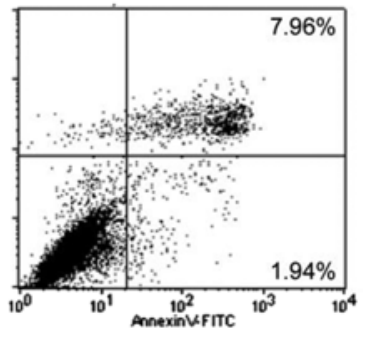

Arecoline $0.1 \mathrm{mM}$

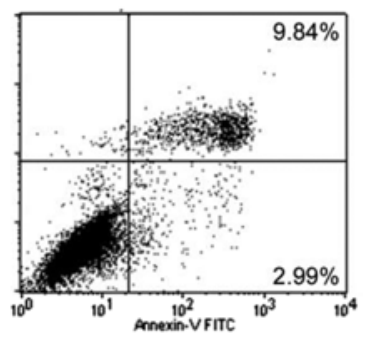

Arecoline $0.4 \mathrm{mM}$

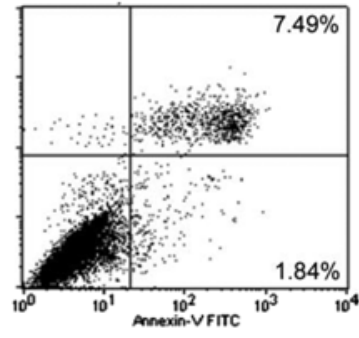

Arecoline $0.2 \mathrm{mM}$

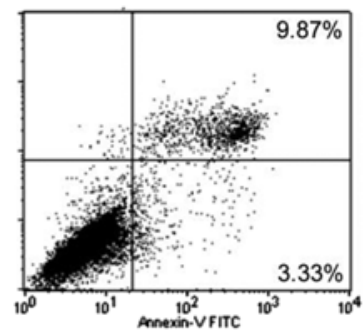

Arecoline $0.5 \mathrm{mM}$

Figure 4. Arecoline-induced apoptosis in $\mathrm{HaCaT}$ and Hel cells. (A) Arecoline dose-dependently induced the apoptosis of HaCaT cells, (B) while arecoline did not induce apoptosis in the Hel cells. Cells were exposed or not to the indicated concentrations of arecoline for $24 \mathrm{~h}$. The percentages of apoptotic cells were determined by flow cytometry as described in Materials and methods. Data are shown as means \pm SD of three independent experiments. ${ }^{*} \mathrm{P}<0.05$, ${ }^{* * *} \mathrm{P}<0.01$ or ${ }^{* * *} \mathrm{P}<0.001$ indicates a significant upregulation of early apoptosis in cells treated with arecoline compared with the untreated control.

comparison to the control cells without exposure to arecoline, exposure to $\geq 0.2 \mathrm{mM}$ arecoline markedly induced HaCaT cell apoptosis (Fig. 4A). Of note, Hel cells displayed much more tolerance to high levels of arecoline-mediated cytotoxicity, since arecoline did not significantly induce Hel cell apoptosis (Fig. 4B). These results indicate that $\mathrm{HaCaT}$ epithelial cells are much more sensitive to arecoline induced apoptosis than Hel fibroblasts in vitro.

Arecoline induces apoptosis-related protein expression and caspase activity. Caspase-3, a member of the caspase family, is expressed in cells as an inactive $32-\mathrm{kDa}$ proenzyme, procaspase-3. During apoptosis, procaspase-3 is activated by cleavage at specific Asp residues to generate active caspase-3, consisting of 17- and 19-kDa subunits. Caspase-3 then cleaves its substrate, poly(ADP-ribose) polymerase (PARP), into 89and $24-\mathrm{kDa}$ fragments. The $\mathrm{BH} 3$ domain-only protein, Bid, is activated upon proteolytic cleavage by caspase- 8 and relays an apoptotic signal from the cell surface to mitochondria. We further detected the expression of caspase-3, cleaved-PARP and Bid by western blot analysis. We found that after exposure to different concentrations of arecoline for $3 \mathrm{~h}$, the expres- 
A

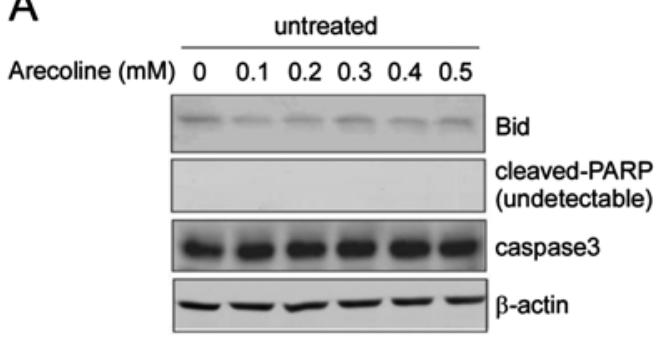

B

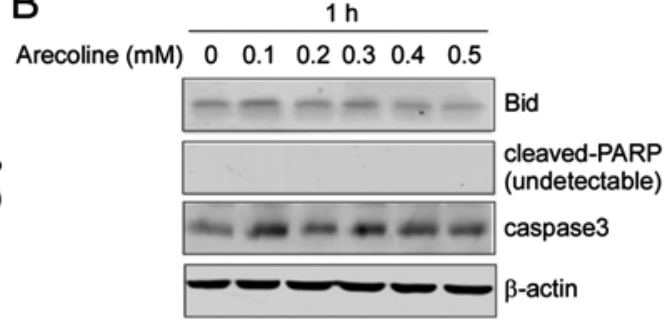

C Arecoline $(\mathrm{mM}) \quad 0 \quad 0.1 \quad 0.2 \quad 0.3 \quad 0.4 \quad 0.5$

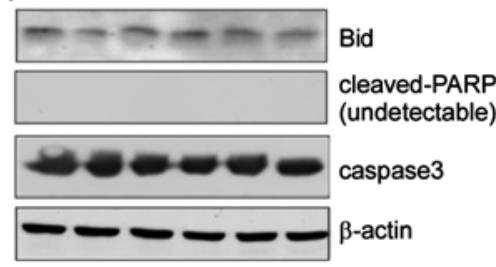

E

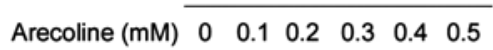

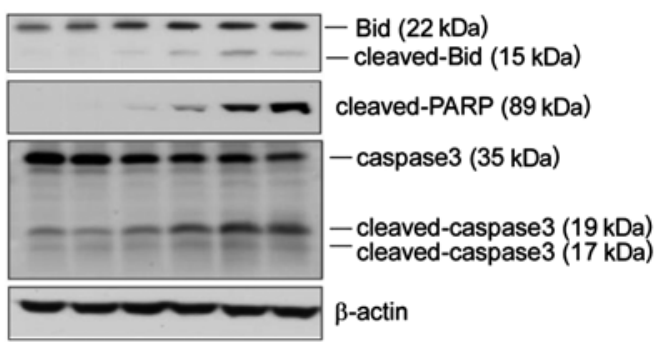

D Arecoline $(\mathrm{mM}) \quad 0 \quad 0.1 \quad 0.2 \quad 0.3 \quad 0.4 \quad 0.5$

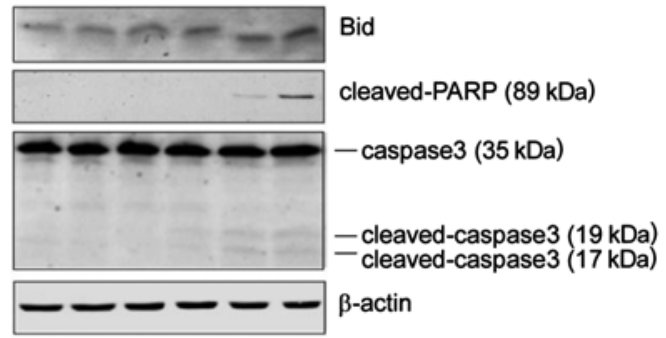

Figure 5. Arecoline induces increased expression of cleaved-Bid, cleaved-PARP and cleaved-caspase-3 in a dose- and time-dependent manner in HaCaT cells. $\mathrm{HaCaT}$ cells were treated with different concentrations of arecoline for $0 \mathrm{~h}(\mathrm{~A}), 1 \mathrm{~h}(\mathrm{~B}), 3 \mathrm{~h}(\mathrm{C}), 6 \mathrm{~h}(\mathrm{D}), 12 \mathrm{~h}(\mathrm{E})$ and $24 \mathrm{~h}(\mathrm{~F})$. Cell lysates were subjected to western blot analysis to determine the expression of Bid, cleaved-Bid, cleaved-PARP, caspase-3 and cleaved-caspase-3. $\beta$-actin was used as an internal control to monitor equal protein sample loading.

sion of caspase-3, cleaved-PARP and Bid showed no obvious change (Fig. 5A-C). As shown in Fig. 5D, a 6-h exposure of $\mathrm{HaCaT}$ cells to $0.4 / 0.5 \mathrm{mM}$ of arecoline resulted in marked activation of caspase- 3 and cleaved-PARP. However, truncated Bid (tBid) was only detected following arecoline exposure for $>12$ h. As shown in Fig. 5E and F, arecoline at $0.2-0.5 \mathrm{mM}$ induced upregulation of cleaved-caspase-3, Bid and PARP in a dose- and time-dependent manner. Our data imply that exposure to high concentrations of arecolin or long-term treatment of arecoline confers a significant cytotoxic effect, and arecoline-induced $\mathrm{HaCaT}$ epithelial cell apoptosis may involve both the death receptor and mitochondrial signaling pathways.

\section{Discussion}

Data from recent epidemiological studies provide overwhelming evidence that the areca nut is the main etiological factor for OSF (16,28-30). Increased collagen synthesis and/or reduced collagen degradation may be involved in the development of this disease. Betel quid chewing affects the wound healing and fibrotic processes in OSF via inducing buccal mucosa fibroblast contraction (31). Areca nut extract (ANE) or arecoline stimulates collagen (32), plasminogen activator inhibitor-1 (PAR-1) (33), cyclooxygenase-2 (34), tissue inhibitor of metalloproteinase-1 (35) expression and decreases collagen phagocytosis (36) in human fibroblasts. Several signaling pathways are deregulated in OSF, such as TGF- $\beta(37,38), \mathrm{NF}-\kappa \mathrm{B}$, JNK, P38 and ERK MAPK $(39,40)$, which may contribute to areca quid chewing-associated OSF.

In order to further investigate the mechanism underlying ANE- or arecoline-induced epithelial atrophy and progressive accumulation of collagen fibers in the lamina propria in OSF, we first assessed the sensitivities of the $\mathrm{HaCaT}$ epithelial cells and the Hel fibroblast cells to arecoline exposure. The salivary concentration of arecoline during BQ chewing has usually been observed to be $\sim 0.3 \mathrm{mM}$, and sometimes has been detected to reach $\sim 0.9 \mathrm{mM}$ (41-43). In addition, Sundqvist et al found that the areca alkaloids, such as arecoline, at a millimolar concentration range is significant for the long-term effects of BQ chewing on buccal mucosa and OSF (44). Therefore, 
we tested the effects of arecoline on human HaCaT epithelial cells and Hel fibroblast cells at concentrations ranging from 0.1 to $0.5 \mathrm{mM}$. Our data demonstrated that arecoline dosedependently promoted morphological changes in HaCaT cells (Fig. 1), but had no obvious effect on Hel cells (Fig. 2). We found that continued exposure to over $0.3 \mathrm{mM}$ arecoline for $48 \mathrm{~h}$ markedly induced $\mathrm{HaCaT}$ cell detachment and rounding. Moreover, a significant proportion of $\mathrm{HaCaT}$ cells displayed contraction and membrane blebbing, which is indicative of cell apoptosis (Fig 1). MTS assay also demonstrated that arecoline inhibited $\mathrm{HaCaT}$ cell, but not Hel cell viability in a dose- and time-dependent manner (Fig 3). Our results imply that a high concentration of arecoline has substantial cytotoxicity and that betel quid chewing can directly induce epithelial cell apoptosis. However, the Hel fibroblast cells were more tolerant to arecoline-mediated cytotoxicity and apoptosis induction.

Cell death is a crucial event for a variety of physiological processes. Its dysfunction leads to severe human diseases that ensue from excessive cell accumulation (e.g., neoplasia and autoimmune disorders) or excessive cell loss (e.g., neurodegenerative diseases) (21). Previous studies have indicated that arecoline-induced human oral epithelial and endothelial cell cycle arrest or apoptosis is involved in the pathogenesis of OSF (45-47). However, the molecular mechanism has not been adequately elucidated. In the present study, we first assessed arecoline-induced apoptosis by flow cytometric analysis. Our results showed that exposure to arecoline at concentrations $>0.2 \mathrm{mM}$ induced HaCaT cell apoptosis in a dose-dependent manner. Notably, the Hel cells were much more resistant to arecoline-induced apoptosis; $0.5 \mathrm{mM}$ arecoline only slightly enhanced Hel cell apoptosis (Fig 4).

To further investigate the mechanisms of arecoline-induced apoptosis in $\mathrm{HaCaT}$ epithelial cells, we examined the protein levels of cleaved-PARP, Bid and caspase- 3 by western blot analysis. We clearly detected caspsae-3 and PARP cleavage following exposure to $>0.3 \mathrm{mM}$ arecoline for $6 \mathrm{~h}$ (Fig 5D). It has been demonstrated that arecoline can activate the intrinsic apoptosis pathway, and that arecoline treatment increases the cleavage of procaspase-9 (48). Moreover, exposure to ANE or arecoline directly deregulated the expression of Bcl-2 family proteins, such as Bcl-2, Bcl-Xl and Bax (49), which disequilibrated mitochondrial controlled apoptosis. Unfortunately, no evidence has illustrated that the extrinsic apoptosis pathway is upregulated in arecoline-induced apoptosis. In this study, we did not detect significant caspase- 8 cleavage in $\mathrm{HaCaT}$ cell (data not shown). However, the downstream target protein of cleaved-caspase-8, Bid, was markedly cleaved in a doseand time-dependent manner following exposure to arecoline (Fig 5E and F), indicating the possibility that other factors or pathways are involved in arecoline-induced Bid activation. Further investigation is warranted to determine whether arecoline directly activates other cell-death modes to induce Bid cleavage and link with the mitochondrial pathway, regulating cell apoptosis.

Overall, the present study demonstrated that arecoline inhibits HaCaT epithelial cell viability and induces apoptosis in a dose- and time-dependent manner, while this observation was not obvious in Hel fibroblast cells. These results suggest that epithelial cells are more sensitive to arecoline-mediated cytotoxicity than fibroblast cells, which may contribute to
BQ chewing-induced epithelial atrophy and progressive accumulation of collagen fibers in OSF. Our findings may aid in the further understanding of the pathogenesis of arecolineassociated OSF, and may facilitate the future development of preventive and therapeutic strategies.

\section{Acknowledgements}

The study was supported by the National Natural Science Foundation of China (81371690) and the International Cooperation Program Funds of the China Hunan Provincial Science and Technology Department (project no. 2012WK4005 and 2013 2013FJ6009).

\section{References}

1. Khan S, Chatra L, Prashanth SK, et al: Pathogenesis of oral submucous fibrosis. J Cancer Res Ther 8: 199-203, 2012.

2. Arakeri $G$ and Brennan PA: Oral submucous fibrosis: an overview of the aetiology, pathogenesis, classification, and principles of management. Br J Oral Maxillofacial Surg 51: 587-593, 2013.

3. Cox SC and Walker DM: Oral submucous fibrosis. A review. Aust Dent J 41: 294-299, 1996.

4. Mahomed F: Oral submucous fibrosis - a potentially malignant condition of growing concern. SADJ 67: 562-565, 2012.

5. Chole RH, Gondivkar SM, Gadbail AR, et al: Review of drug treatment of oral submucous fibrosis. Oral Oncol 48: 393-398, 2012.

6. Paissat DK: Oral submucous fibrosis. Int J Oral Surg 10: 307-312, 1981.

7. Aziz SR: Oral submucous fibrosis: an unusual disease. J N J Dent Assoc 68: 17-19, 1997.

8. Warnakulasuriya S, Johnson NW and van der Waal I: Nomenclature and classification of potentially malignant disorders of the oral mucosa. J Oral Pathol Med 36: 575-580, 2007.

9. Tilakaratne WM, Klinikowski MF, Saku T, et al: Oral submucous fibrosis: review on aetiology and pathogenesis. Oral Oncol 42: 561-568, 2006.

10. Walvekar RR, Chaukar DA, Deshpande MS, et al: Verrucous carcinoma of the oral cavity: a clinical and pathological study of 101 cases. Oral Oncol 45: 47-51, 2009.

11. Thomas SJ, Bain CJ, Battistutta D, et al: Betel quid not containing tobacco and oral cancer: a report on a case-control study in Papua New Guinea and a meta-analysis of current evidence. Int J Cancer 120: 1318-1323, 2007.

12. Ko YC, Huang YL, Lee CH, et al: Betel quid chewing, cigarette smoking and alcohol consumption related to oral cancer in Taiwan. J Oral Pathol Med 24: 450-453, 1995.

13. Panigrahi GB and Rao AR: Chromosome-breaking ability of arecoline, a major betel-nut alkaloid, in mouse bone-marrow cells in vivo. Mutat Res 103: 197-204, 1982.

14. Chou WW, Guh JY, Tsai JF, et al: Arecoline-induced phosphorylated p53 and p21(WAF1) protein expression is dependent on ATM/ATR and phosphatidylinositol-3-kinase in clone-9 cells. J Cell Biochem 107: 408-417, 2009.

15. Stich HF, Stich W and Lam PP: Potentiation of genotoxicity by concurrent application of compounds found in betel quid: arecoline, eugenol, quercetin, chlorogenic acid and $\mathrm{Mn}^{2+}$. Mutat Res 90: 355-363, 1981.

16. Jeng JH, Chang MC and Hahn LJ: Role of areca nut in betel quid-associated chemical carcinogenesis: current awareness and future perspectives. Oral Oncol 37: 477-492, 2001.

17. Dasgupta R, Saha I, Pal S, et al: Immunosuppression, hepatotoxicity and depression of antioxidant status by arecoline in albino mice. Toxicology 227: 94-104, 2006.

18. Grutter MG: Caspases: key players in programmed cell death. Curr Opin Struct Biol 10: 649-655, 2000.

19. Crowder RN and El-Deiry WS: Caspase-8 regulation of TRAILmediated cell death. Exp Oncol 34: 160-164, 2012.

20. Cory S and Adams JM: The Bcl2 family: regulators of the cellular life-or-death switch. Nat Rev Cancer 2: 647-656, 2002.

21. Ghiotto F, Fais F and Bruno S: BH3-only proteins: the deathpuppeteer's wires. Cytometry A 77: 11-21, 2010. 
22. Tait SW and Green DR: Mitochondria and cell death: outer membrane permeabilization and beyond. Nat Rev Mol Cell Biol 11: 621-632, 2010.

23. Kantari $\mathrm{C}$ and Walczak $\mathrm{H}$ : Caspase- 8 and bid: caught in the act between death receptors and mitochondria. Biochim Biophys Acta 1813: 558-563, 2011.

24. Wang K, Yin XM, Chao DT, et al: BID: a novel BH3 domainonly death agonist. Genes Dev 10: 2859-2869, 1996.

25. Li H, Zhu H, Xu CJ, et al: Cleavage of BID by caspase 8 mediates the mitochondrial damage in the Fas pathway of apoptosis. Cell 94: 491-501, 1998.

26. Luo X, Budihardjo I, Zou H, et al: Bid, a Bcl2 interacting protein, mediates cytochrome $\mathrm{c}$ release from mitochondria in response to activation of cell surface death receptors. Cell 94: 481-490, 1998

27. Gross A, Yin XM, Wang K, et al: Caspase cleaved BID targets mitochondria and is required for cytochrome $c$ release, while BCL-XL prevents this release but not tumor necrosis factor-R1/ Fas death. J Biol Chem 274: 1156-1163, 1999.

28. Reichart PA: Oral cancer and precancer related to betel and miang chewing in Thailand: a review. J Oral Pathol Med 24: 241-243, 1995.

29. Trivedy CR, Craig G and Warnakulasuriya S: The oral health consequences of chewing areca nut. Addict Biol 7: 115-125, 2002.

30. IARC Working Group on the Evaluation of Carcinogenic Risks to Humans: Betel-quid and areca-nut chewing and some areca-nut derived nitrosamines. IARC Monogr Eval Carcinog Risks Hum 85: 1-334, 2004.

31. Chang MC, Lin LD, Wu HL, et al: Areca nut-induced buccal mucosa fibroblast contraction and its signaling: a potential role in oral submucous fibrosis - a precancer condition. Carcinogenesis 34: 1096-1104, 2013.

32. Li X, Ling TY, Gao YJ, Tang, DS, Li WH: Arecoline and oral keratinocytes may affect the collagen metabolism of fibroblasts J Oral Pathol Med 38: 422-426, 2009.

33. Yang SF, Hsieh YS, Tsai $\mathrm{CH}$, et al: Increased plasminogen activator inhibitor-1/tissue type plasminogen activator ratio in oral submucous fibrosis. Oral Dis 13: 234-238, 2007.

34. Chiang SL, Chen $\mathrm{PH}$, Lee $\mathrm{CH}$, et al: Up-regulation of inflammatory signalings by areca nut extract and role of cyclooxygenase-2 $-1195 \mathrm{G}>\mathrm{a}$ polymorphism reveal risk of oral cancer. Cancer Res 68: 8489-8498, 2008.

35. Shieh DH, Chiang LC and Shieh TY: Augmented mRNA expression of tissue inhibitor of metalloproteinase-1 in buccal mucosal fibroblasts by arecoline and safrole as a possible pathogenesis for oral submucous fibrosis. Oral Oncol 39: 728-735, 2003.

36. Shieh DH, Chiang LC, Lee CH, et al: Effects of arecoline, safrole, and nicotine on collagen phagocytosis by human buccal mucosal fibroblasts as a possible mechanism for oral submucous fibrosis in Taiwan. J Oral Pathol Med 33: 581-587, 2004.
37. Khan I, Kumar N, Pant I, et al: Activation of TGF-beta pathway by areca nut constituents: a possible cause of oral submucous fibrosis. PloS One 7: e51806, 2012.

38. Kale AD, Mane DR and Shukla D: Expression of transforming growth factor beta and its correlation with lipodystrophy in ora submucous fibrosis: an immunohistochemical study. Med Oral Patol Oral Cir Bucal 18: e12-e18, 2013.

39. Yu CC, Tsai CH, Hsu HI, et al: Elevation of S100A4 expression in buccal mucosal fibroblasts by arecoline: involvement in the pathogenesis of oral submucous fibrosis. PloS One 8: e55122, 2013.

40. Deng YT, Chen HM, Cheng SJ, et al: Arecoline-stimulated connective tissue growth factor production in human buccal mucosal fibroblasts: modulation by curcumin. Oral Oncol 45: e99-e105, 2009.

41. Nair J, Ohshima H, Friesen M, et al: Tobacco-specific and betel nut-specific $\mathrm{N}$-nitroso compounds: occurrence in saliva and urine of betel quid chewers and formation in vitro by nitrosation of betel quid. Carcinogenesis 6: 295-303, 1985.

42. Shirname LP, Menon MM, Nair J, et al: Correlation of mutagenicity and tumorigenicity of betel quid and its ingredients. Nutr Cancer 5: 87-91, 1983.

43. Cox S, Vickers ER, Ghu S and Zoellner H: Salivary arecoline levels during areca nut chewing in human volunteers. J Oral Pathol Med 39: 465-469, 2010.

44. Sundqvist K, Liu Y, Nair J, et al: Cytotoxic and genotoxic effects of areca nut-related compounds in cultured human buccal epithelial cells. Cancer Res 49: 5294-5298, 1989.

45. Lee PH, Chang MC, Chang WH, et al: Prolonged exposure to arecoline arrested human $\mathrm{KB}$ epithelial cell growth: regulatory mechanisms of cell cycle and apoptosis. Toxicology 220: 81-89, 2006.

46. Tseng SK, Chang MC, Su CY, et al: Arecoline induced cell cycle arrest, apoptosis, and cytotoxicity to human endothelial cells. Clin Oral Investig 16: 1267-1273, 2012.

47. Zhou ZS, Li M, Gao F, et al: Arecoline suppresses HaCaT cell proliferation through cell cycle regulatory molecules. Oncol Rep 29: 2438-2444, 2013

48. Shih YT, Chen PS, Wu CH, et al: Arecoline, a major alkaloid of the areca nut, causes neurotoxicity through enhancement of oxidative stress and suppression of the antioxidant protective system. Free Radic Biol Med 49: 1471-1479, 2010.

49. Cheng HL, Su SJ, Huang LW, et al: Arecoline induces HA22T/ VGH hepatoma cells to undergo anoikis - involvement of STAT3 and RhoA activation. Mol Cancer 9: 126, 2010. 